\title{
RELATIONSHIP BETWEEN CERTAIN CERAMIC ROOFING TILE CHARACTERISTICS AND
} BIODETERIORATION

\author{
M.F. GAZULLA ${ }^{(1)}$, E. SÁNCHEZ ${ }^{(1)}$, J.M. GONZÁLEZ ${ }^{(2)}$, M.C. PORTILLO ${ }^{(2)}$, M. \\ ORDUÑ ${ }^{(1)}$ \\ (1) Instituto de Tecnología Cerámica. Asociación de Investigación de las Industrias \\ Cerámicas (ITC-AICE). Universitat Jaume I. Castellon. Spain. \\ (2) Instituto de Recursos Naturales y Agrobiología (IRNAS). CSIC. Seville. Spain
}

\section{Abstract}

This paper examines the relationship of certain red ceramic roofing tile properties to roofing tile biodeterioration. The following properties were studied: apparent porosity, roughness, and the presence or absence of two types of coatings.

The effect of apparent porosity was studied by varying the peak firing temperature of a standard industrial red ceramic roofing tile composition and by preparing several clay mixtures, of different chemical and mineralogical composition, that were fired at various peak temperatures. The effect of roofing tile roughness was determined by either polishing or sanding fired standard red roofing tiles. A waterproof ceramic glaze coating and a photocatalytic coating were formulated to analyse the effect of the presence of different types of coatings. Roofing tile bioreceptivity was evaluated with a method developed in a previous study using the cyanobacteria Oscillatoria $\mathrm{sp}$, which enabled roofing tile resistance to microbial colonization to be determined.

As expected, bioreceptivity rose as apparent porosity (measured as water absorption) increased, enabling possible water retention, which favours biological growth. Similarly, greater roughness encouraged micro-organism adhesion and 
raised bioreceptivity. It was found that, after prolonged exposure periods (several months) under very favourable conditions for biological colonization, roofing tiles coated with the waterproof ceramic glaze were colonized. However, glazed standard red roofing tiles covered with a $\mathrm{TiO}_{2}$ photocatalytic coating exhibited practically no biological growth under the test conditions used, even after long exposure times, owing to the chemical-physical effect of the $\mathrm{TiO}_{2}$-based coating.

\section{Keywords}

Bioreceptivity, roofing tiles, surfaces, traditional ceramics, $\mathrm{TiO}_{2}$.

\section{Introduction}

A frequent problem in roofing materials is biological colonization by pioneer communities such as cyanobacteria, bacteria, algae, and fungi. These favour the invasion of secondary communities (lichens and mosses) and may subsequently include vascular plant growth, which can have ruinous effects on buildings.

Numerous studies have described the damage caused in materials as a result of biological activity. Studies have thus addressed the interaction mechanisms between lichens and construction materials [1, 2], the relationship of materials degradation to the formation of compounds from substances produced by lichens [3] such as oxalic acid segregation [4], and the role of these compounds in monument deterioration and soil formation [5]. Another study [6] measured roofing tile physical properties, such as texture, specific surface area, and surface roughness, while biodeterioration was observed to decrease when firing temperature increased. The effect of lichens on different types of roofing tiles (20-30 years old, with glass and copper compound additions) was analysed [7], their deterioration being determined by XRD, FTIR, SEM-EDS, expansion, porosimetry, and chemical analysis. 
A further study [8] set out the problems occurring in roofing tiles covered by a layer of silicone after a certain period of service, since the silicone layer had properties that differed considerably from those of the roofing tile composition.

Although many papers have addressed biodeterioration in construction materials in general (concrete, natural stone, ceramic roofing tiles, and bricks), no in-depth study has been conducted on the relationship of process variables to resulting ceramic materials characteristics, which could enable products with enhanced bio-resistance to be designed. This has been partly due to the unavailability of a reliable standard method for rapidly evaluating biodeterioration in a reproducible manner.

The present research group carried out a first study [9] in which colonized roofing tiles were characterized, isolating a series of micro-organisms that were then used to perform bioreceptivity tests. A rapid method of determining bioreceptivity using an alga was developed in a second study [10], since the only way of determining resistance to biocolonization had previously been by subjecting materials to weathering, which was influenced by many variables: temperature, humidity, precipitation, pollution, etc. The bioreceptivity of certain materials was also related to porosity and surface roughness, and it was concluded that an in-depth study was needed of the variables that affected the bioreceptivity of ceramic materials.

On the other hand, the literature also reports that $\mathrm{TiO}_{2}$-based photocatalytic coatings can reduce biocolonization $[11,12]$ by a twofold effect, involving a chemical process that fosters oxidation of organic matter and a physical process that reduces the contact angle and promotes self-cleaning by water, decreasing micro-organism adhesion.

The present study examines the relationship of different red ceramic roofing tile characteristics (apparent porosity, roughness, and the presence or absence of a waterproof ceramic glaze coating) to roofing tile bioreceptivity, using a previously 
developed method to analyse bioreceptivity [10]. The effect of applying a $\mathrm{TiO}_{2}-$ based photocatalytic coating on to glazed ceramic roofing tiles was similarly studied.

\section{Experimental part}

\subsection{Materials}

The materials used in studying the effect of ceramic roofing tile apparent porosity and roughness, and the presence of a ceramic glaze and a photocatalytic coating are detailed below.

- The effect of apparent porosity was studied using two different approaches. On the one hand, the peak firing temperature was varied of an unfired, industrially prepared, standard red ceramic roofing tile (referenced SRT), which yielded materials with different apparent porosities owing to the ensuing changes in the sintering process and formation of new crystalline or glassy phases. On the other hand, clay mixtures (referenced C-1, C-2, and C-3) of different chemical and mineralogical composition were prepared in the laboratory, basically varying the calcite content in order to obtain fired specimens with very different apparent porosities. The chemical and mineralogical composition of the SRT samples and of the clay mixtures are detailed in Table 1. The approximate quantities of alkaline-earth carbonates (expressed as calcium carbonate) in the C-1, C-2, and C-3 compositions were 3, 13, and $8 \%$ respectively, while that in the SRT composition was $9 \%$. 
Table 1: Chemical and mineralogical composition of the standard red ceramic roofing tile (SRT) samples and of the clay mixtures (C-1, C-2, and C-3)

\begin{tabular}{|c|c|c|c|c|c|c|c|c|c|c|c|}
\hline & \multicolumn{10}{|c|}{$\begin{array}{c}\text { Chemical composition } \\
\text { Oxides (\%) }\end{array}$} & \multirow{2}{*}{$\begin{array}{l}\text { Mineralogical } \\
\text { composition }\end{array}$} \\
\hline & $\mathrm{SiO}_{2}$ & $\mathrm{Al}_{2} \mathrm{O}_{3}$ & $\mathrm{Fe}_{2} \mathrm{O}_{3}$ & $\mathrm{CaO}$ & MgO & $\mathrm{Na}_{2} \mathrm{O}$ & $\mathrm{K}_{2} \mathrm{O}$ & $\mathrm{TiO}_{2}$ & $\mathrm{P}_{2} \mathrm{O}_{5}$ & $\begin{array}{c}\text { LOI } \\
\left(1000^{\circ} \mathrm{C}\right)\end{array}$ & \\
\hline SRT & 60.3 & 15.6 & 5.66 & 3.25 & 2.73 & 0.37 & 3.95 & 0.74 & 0.12 & 7.3 & $\begin{array}{c}\text { Quartz } \\
\text { Illite/Muscovite } \\
\text { Kaolinite } \\
\text { Calcite } \\
\text { K-feldspar } \\
\text { Hematites }\end{array}$ \\
\hline $\begin{array}{l}\text { Mixture } \\
\text { C-1 }\end{array}$ & 64.0 & 16.6 & 5.71 & 1.72 & 1.62 & 0.51 & 3.38 & 0.82 & 0.12 & 5.42 & Illite/Muscovite \\
\hline $\begin{array}{l}\text { Mixture } \\
\text { C-2 }\end{array}$ & 58.4 & 15.4 & 5.24 & 5.73 & 1.81 & 0.48 & 3.45 & 0.70 & 0.13 & 8.59 & $\begin{array}{l}\text { K-feldspar } \\
\text { Quartz }\end{array}$ \\
\hline $\begin{array}{l}\text { Mixture } \\
\text { C-3 }\end{array}$ & 60.3 & 15.8 & 5.40 & 4.39 & 1.75 & 0.49 & 3.43 & 0.73 & 0.13 & 7.54 & Dolomite \\
\hline
\end{tabular}

- To study the effect of surface roughness, SRT samples were fired in industrial conditions with a firing cycle of 24 hours and peak firing temperature of $950 \stackrel{\circ}{\circ}$. The resulting samples were referenced FSRT-ind. FSRT-ind samples were then subjected either to polishing (hereafter FSRT-polished samples) or to sanding (hereafter FSRT-sand samples).

- The effect of the type of coating was studied using SRT test pieces coated with a ceramic glaze, which were fired under conditions resembling those used in industrial practice (hereafter FSRT-glazed samples), and FSRT-glazed samples to which a commercial photocatalytic coating [Nano-X $\mathrm{GmbH}$ ] was additionally applied, hereafter FSRT-glazed-Ti samples.

The use of different types of micro-organisms, their ability to colonize roofing tiles, and their detectability were reviewed in a previous paper [10], in which an accelerated method of analysing bioreceptivity was put forward. That method, in which Oscillatoria sp. PCC 9325 was used as a model micro-organism, has been used in the roofing tile bioreceptivity tests in this study. 


\subsection{Experimental procedure}

\subsubsection{Preparation of the materials}

\subsubsection{Effect of apparent porosity}

The effect of apparent porosity was evaluated by modifying the peak firing temperature of a standard red ceramic roofing tile (SRT) composition and by preparing different clay mixtures (C-1, C-2, and C-3).

SRT samples were thus fired at different peak temperatures, reproducing as closely as possible the industrial firing cycle. The peak firing temperatures were 945,970 , 995 , and $1020^{\circ} \mathrm{C}$, and the residence time at these temperatures was $90 \mathrm{~min}$. The fired samples were referenced FSRT-945, FSRT-970, FSRT-995, and FSRT-1020, respectively. A SRT sample was also similarly fired at the typical peak firing temperature used in industry $\left(950^{\circ} \mathrm{C}\right)$ and referenced FSRT-ind.

In order to obtain ceramic specimens with a wide range of porosities, test pieces were formed from clay mixtures $(\mathrm{C}-1, \mathrm{C}-2$, and $\mathrm{C}-3)$ by pressing. (Forming by pressing (instead of extrusion) simplified the composition preparation procedure and reduced the effect of drying on resulting test piece quality.) Before forming, the clay mixtures were milled in ball mills for 10 minutes. The milled and dried solid was then sprayed with water to obtain a powder with a moisture content of $5.5 \%$ (on a dry basis). Disks, $4 \mathrm{~cm}$ in diameter, were pressed from the moistened powder at a pressing pressure of $250 \mathrm{~kg} \cdot \mathrm{cm}^{-2}$. This pressing powder preparation method has been described elsewhere [13]. The resulting test pieces were then fired at different peak temperatures (C-1 at $1100^{\circ} \mathrm{C}, \mathrm{C}-2$ at $1125^{\circ} \mathrm{C}$, and $\mathrm{C}-3$ at $\left.1150^{\circ} \mathrm{C}\right)$.

Water absorption, which is a measure of apparent porosity, was determined in the SRT roofing tiles fired at different temperatures and in the fired test disks prepared 
from the clay mixtures by immersing the pieces in boiling water for 2 hours, according to the procedure described in standard UNE-EN ISO 10545-3:1997.

\subsubsection{Effect of roughness}

Roofing tiles were prepared with different roughness from FSRT-ind samples either by polishing, thus obtaining a FSRT-polished sample that was smoother than the starting FSRT-ind tile, or by sanding, which yielded a FSRT-sand sample that was rougher than the starting FSRT-ind tile.

Surface roughness was determined with a HOMMELWERKE model T8000 roughness tester, using a pick-up with a diamond tip of $90^{\circ}$ curvature and $5 \mu \mathrm{m}$ radius. A topography consisting of 101 profiles, $10 \mathrm{~mm}$ long, spaced at $200 \mu \mathrm{m}$ from each other, was obtained, covering an area of $10 \times 10 \mathrm{~mm}$ on each studied surface. The roughness parameters were calculated using a $2.5-\mathrm{mm}$ cut-off. The characteristic roughness parameter $R_{a}$ was calculated for each profile, $R_{a}$ being the arithmetic mean of the absolute values of the distance of the points that make up the profile to a mean line, from the equation:

$$
R_{a}=\frac{1}{l_{m}} \int_{0}^{l m}|y(x)| d x
$$

where $I_{m}$ is the length of the profile drawn during the test [14].

\subsubsection{Effect of the type of coating}

A red ceramic glaze composition was formulated that yielded a waterproof fired glaze coating, whose appearance was designed to resemble that of the fired SRT sample as closely as possible. The following components were used for this purpose: a frit consisting mainly of $\mathrm{SiO}_{2}, \mathrm{Al}_{2} \mathrm{O}_{3}, \mathrm{~B}_{2} \mathrm{O}_{3}, \mathrm{CaO}, \mathrm{BaO}$, and $\mathrm{ZnO}$; a red ceramic pigment; and kaolin. The mixture of raw materials and additives (a sodium polyacrylate-based dispersant and a carboxymethylcellulose-based thickener) was ground, together with the necessary amount of water, in a laboratory ball mill for 30 
$\min$. The glaze composition is given in Table 2. A layer, about $300 \mu \mathrm{m}$ thick, of the resulting suspension was applied on to the surface of $5 \times 5 \mathrm{~cm}$ pieces of the standard red roofing tile (SRT), reproducing industrial practice. The glazed test pieces were fired according to the firing cycle described in the foregoing section at a peak temperature of $970 \stackrel{\circ}{\circ}$, yielding the samples referenced FSRT-glazed.

Table 2. Composition of the prepared ceramic glaze

\begin{tabular}{|c|c|}
\hline Raw materials & \% by weight \\
\hline Water & 35 \\
\hline Frit & 55.5 \\
\hline Red pigment & 4.0 \\
\hline Kaolin & 5.1 \\
\hline Deflocculant & 0.2 \\
\hline Thickener & 0.2 \\
\hline
\end{tabular}

To obtain tile specimens with a photocatalytic coating, a commercial photocatalytic dispersion based on a $\mathrm{TiO}_{2}$ sol-gel was applied on to $5 \times 5 \mathrm{~cm}$ test pieces of the fired glazed red roofing tile (FSRT-glazed). The photocatalytic coating consisted of a twolayer system: a $\mathrm{SiO}_{2}$-based colloidal dispersion, which was applied first in order to obtain a suitable ceramic surface, and a $\mathrm{TiO}_{2}$-based application.

The two layers making up the photocatalytic coating were applied by spraying the colloidal dispersions under appropriate operating conditions to obtain the thinnest possible total coating thickness $(<10 \mu \mathrm{m})$. The coated pieces were then heat treated at either $200{ }^{\circ} \mathrm{C}$ or $600^{\circ} \mathrm{C}$ for 10 minutes (hereafter FSRT-glazed-Ti samples).

\subsubsection{Bioreceptivity test}

The bioreceptivity test was conducted on different samples using the set-up shown in Figure 1. The set-up allows accelerated testing of micro-organism growth on roofing tile surfaces, using an instrument that enables information to be obtained from the initial moments of colonization, unlike other microbiological test methods [15] that take at least 2 or 3 weeks to perform. 
The reference roofing tile (FSRT-ind) displayed no characteristic or treatment aimed at delaying or inhibiting colonization and could be used repeatedly as a control tile to assure that the colonization test had run its normal course and that no phenomenon had occurred that might bias the results (e.g. deficiencies in Oscillatoria growth).

The biological colonization on the surface of the test roofing tiles was quantified by determining two parameters: fluorescence intensity and colonization height, as described elsewhere [10], using a pulse-amplitude-modulated (PAM) fluorometer (Heinz Walz GmbH, Effeltrich, Germany).

Chlorophyll fluorescence over the scanned area was plotted using the analytical software package SigmaPlot v.8.0 (SPSS Inc., Chicago). Bioreceptivity was quantified by using the distance and fluorescence per unit of area colonized by the Oscillatoria strain in a given time period. The colonization space was estimated from the vertical distance where the fluorescence intensity measured over the roofing tile coupon surface showed its maximum negative derivative. Bioreceptivity was measured on at least three replicas of each sample [10].

In addition, in the study of the glazed roofing tiles with a photocatalytic coating, in which the pieces needed to be subjected to UV radiation, tests were conducted with Oscillatoria used in the bioreceptivity tests, subjecting the Oscillatoria to this radiation. The remaining bioreceptivity test conditions followed the method described elsewhere [10]. The results indicated that the Oscillatoria resisted the UV radiation to which it was subjected, though the radiation slightly delayed the start of its development.

The method used to determine bioreceptivity is more accurate and reproducible than other methods described in the literature [15], since it is unaffected by features such as roofing tile colour, roughness, or type of coating. This is because only the fluorescence of the micro-organism chlorophyll is measured. 
The method also has the advantage of not requiring a scanning electron microscope (SEM) $[6,7]$, whose high cost is an obstacle to making that a standard method in the industrial determination of bioreceptivity. In addition, the micro-organism used in the proposed method allows material to be tested in a very short period of time (from 10 days to about two weeks), compared with the time needed by other methods in the literature [6].

\section{Results and discussion}

\subsection{Influence of apparent porosity on biological colonization}

The results obtained in the PAM fluorometer measurement of the standard red roofing tiles fired at different temperatures (FSRT series) are shown in Figure 2. As reported in the previous paper [10], the surface of the culture medium locates near the sample bottom line. Furthermore, fluorescence is expressed in arbitrary units and 0 corresponds to the minimum fluorescence value. The resulting water absorption data of these fired roofing tiles, as well as the colonization heights obtained on these pieces by the bioreceptivity test [10], are detailed in Table 3.

Table 3: Water absorption and colonization height in the standard red roofing tiles fired at different temperatures (FSRT series) to determine the influence of apparent porosity

\begin{tabular}{|c|c|c|}
\hline SAMPLE & $\begin{array}{c}\text { Apparent porosity } \\
\text { (water absorption \%) }\end{array}$ & $\begin{array}{c}\text { Colonization } \\
\text { height }(\mathbf{m m})\end{array}$ \\
\hline FSRT-ind & 10.6 & $12.9 \pm 0.9$ \\
\hline FSRT-945 & 10.0 & $13.1 \pm 1.1$ \\
\hline FSRT-970 & 9.3 & $12.5 \pm 1.0$ \\
\hline FSRT-995 & 9.0 & $15.4 \pm 0.9$ \\
\hline FSRT-1020 & 8.0 & $16.3 \pm 1.0$ \\
\hline
\end{tabular}

The table shows that the standard red roofing tiles fired at different temperatures exhibited water absorption values between 8 and 10\%, displaying relatively little variation despite the wide range of tested peak firing temperatures. This minor 
variation in apparent porosity is a result of the FSRT composition, since it contains a high quantity of alkaline-earth carbonates (about $9 \%$, expressed as $\mathrm{CaCO}_{3}$ ), which allows tile size to stabilize when the calcium oxide resulting from calcium carbonate decomposition reacts with silica and alumina from clay mineral decomposition, thus delaying sintering start. Such behaviour is typical of calcareous compositions used in the manufacture of traditional ceramics [16], which are also widely used in Spain for roofing tile manufacture.

At these water absorption values, no significant differences were observed in bioreceptivity, based on the fluorescence values (Figure 2) and colonization heights (Table 3), possibly because these porosity values were sufficiently high to enable the material to retain the necessary quantity of water for biocolonization to take place. That is, there seems to be a porosity threshold value that enables biocolonization to occur.

The water absorption data of the test pieces prepared from clay mixtures C-1, C-2, and C-3, which were fired at different peak firing temperatures from those of the FSRT series in order to obtain a more extensive range of apparent porosity values, are detailed in Table 4. The resulting apparent porosity values (measured as water absorption) varied, in fact, much more widely than the variations that might be expected in industrial practice. To be noted is the comparatively low porosity of C-1 as a result of the low quantity of alkaline-earth carbonates.

Table 4: Water absorption and colonization height in the fired test pieces obtained from clay mixtures C-1, C-2, and C-3

\begin{tabular}{|c|c|c|}
\hline SAMPLE & $\begin{array}{c}\text { Apparent porosity } \\
\text { (water absorption \%) }\end{array}$ & $\begin{array}{c}\text { Colonization } \\
\text { height (mm) }\end{array}$ \\
\hline C-1 & 0.84 & $6.5 \pm 0.5$ \\
\hline C-2 & 11.9 & $17.0 \pm 0.9$ \\
\hline C-3 & 8.1 & $18.3 \pm 1.6$ \\
\hline
\end{tabular}


Figure 3 shows photographs of the biological colonization on fired test pieces obtained from clay mixtures C-1, C-2, and C-3 after 14 days' exposure. Figure 4 presents the corresponding PAM fluorometer measurements.

The two figures show that there was a considerable difference in colonization between the fired $\mathrm{C}-1$ pieces and the fired $\mathrm{C}-2$ and $\mathrm{C}-3$ pieces. This was to be expected since the fired C-1 piece displayed much lower apparent porosity (practically zero), entailing lower bioreceptivity, i.e. lower colonization height (Table 4).

The data in Tables 3 and 4 have been plotted in the form colonization height versus water absorption in Figure 5.

The figure shows that colonization height (bioreceptivity) increased when water absorption (apparent porosity) rose, because water retention favours microbiological growth, as indicated in the literature [6, 7].

It may be noted, however, that the colonization heights (bioreceptivity) obtained for apparent porosity values between $8 \%$ and $12 \%$ displayed no significant differences. This could be due to apparent porosity already being sufficiently high to retain the amount of water needed for biological colonization to occur.

\subsection{Influence of roughness on biological colonization}

Figure 6 shows photographs of the biological colonization on the fired standard red roofing tile (FSRT-ind), sanded standard red roofing tile (FSRT-sand), and polished standard red roofing tile (FSRT-polished) after 10 days' exposure. Figure 7 shows the PAM fluorometer measurements of these samples. A considerable difference in colonization may be clearly observed between the FSRT-sand sample and the other two, the FSRT-sand sample displaying greater bioreceptivity, which was to be expected since greater roughness encourages micro-organism adhesion on the surface. The differences in colonization between the FSRT-ind and FSRT-polished 
samples are smaller, though colonization was lower on the smoother sample surface (FSRT-polished).

The surface roughness parameter $\left(R_{a}\right)$ is plotted versus colonization height of the three test roofing tiles in Figure 8. The figure shows a good correlation between roughness and bioreceptivity of the tested roofing tiles: the rougher the surface, the higher the bioreceptivity, which matches the results reported in the literature for this type of material $[6,10]$. It also highlights the potential importance of adjusting ceramic roofing tile roughness by modifying process variables, such as the milling process and/or firing temperature, in order to design materials with enhanced resistance to biodeterioration.

\subsection{Influence of the type of coating on biological colonization}

\subsubsection{Glazed standard red roofing tile with a waterproof ceramic glaze}

Figure 9 shows photographs of the biological colonization of the fired standard red roofing tile (FSRT-ind) and the glazed standard red roofing tile (FSRT-glazed) after 15-day exposure. The PAM fluorometer measurements are depicted in Figure 10. The differences in biocolonization can be clearly observed, the application of a ceramic glaze coating leading to a notable decrease in biocolonization owing to the reduction in roofing tile surface porosity.

The colonization height and water absorption data of the FSRT-ind sample and of the glazed surface of the FSRT-glazed sample are detailed in Table 5.

Table 5: Water absorption and colonization height of the glazed (FSRT-glazed) and unglazed (FSRT-ind) standard red roofing tiles

\begin{tabular}{|c|c|c|}
\hline RED TILE & Water absorption (\%) & Colonization height \\
\hline FSRT-glazed & $0.3^{(1)}$ & $<1 \pm 0.1$ \\
\hline FSRT-ind & 10.6 & $12.9 \pm 0.9$ \\
\hline
\end{tabular}

(1) Value corresponding to the glazed surface 
The results indicate that the glazed roofing tile displayed practically no biological growth on its surface after the test time, bioreceptivity therefore being practically zero, which was to be expected since apparent porosity of the FSRT-glazed sample was below $0.5 \%$.

Comparison of the colonization height on the fired $\mathrm{C}-1$ piece (Table 4) with that on the FSRT-glazed sample (Table 5) shows, however, that the C-1 piece exhibited higher biocolonization than the FSRT-glazed sample, despite both having very low apparent porosity (water absorption $<1 \%$ ). This difference could be due to the lower roughness of the glazed roofing tile $(1.2 \pm 0.1 \mu \mathrm{m})$ compared with that of the unglazed roofing tile $(3.3 \pm 0.3 \mu \mathrm{m})$.

\subsubsection{Roofing tile with photocatalytic coating}

The results obtained in the biocolonization tests of the fired standard red roofing tiles (FSRT-ind), glazed standard red roofing tiles (FSRT-glazed), and glazed standard red roofing tiles covered with a photocatalytic coating (FSRT-glazed-Ti) that was subsequently heat treated at either $200^{\circ} \mathrm{C}$ or $600^{\circ} \mathrm{C}$ are shown in Figure 11.

The roofing tiles with a photocatalytic coating are observed to display less biological colonization than the others after a long exposure time (30 days). On the other hand, the roofing tile with a photocatalytic coating subjected to heat treatment at a

higher temperature appeared to exhibit less biocolonization than that with a photocatalytic coating treated at a lower temperature. These results could be related to the greater or lesser photocatalytic activity of the coatings and/or to coating durability in relation to the heat treatment used, so that further experimentation is required in order to evaluate the photocatalytic activity of such coatings.

With a view to examining further the effect of the photocatalytic coating after prolonged exposure times, glazed standard red roofing tile (FSRT-glazed) and glazed standard red roofing tile with a photocatalytic coating (FSRT-glazed-Ti) heat 
treated at $600{ }^{\circ} \mathrm{C}$ were subjected to the bioreceptivity test for 4 months. The resulting colonization is presented in Figure 12, which shows the difference in colonization after 4-month exposure.

The reason that the FRST-glazed sample without a photocatalytic coating exhibited biocolonization after prolonged periods of time could be that, though it had very low water absorption, there was some roughness that might favour micro-organism adhesion. Further study is required in this regard.

It may be observed, however, that the $\mathrm{TiO}_{2}$-based photocatalytic coating reduced biocolonization. This type of coating gives rise to a chemical process that fosters oxidation of organic matter $[11,12]$, as well as a physical process that reduces the contact angle and promotes self-cleaning by water, decreasing micro-organism adhesion. The results obtained in the $\mathrm{TiO}_{2}$-coated pieces agree with findings reported on concrete samples [17], though a different test method was used in that study.

\section{Conclusions}

The relationship of certain red ceramic roofing tile properties to roofing tile biodeterioration was studied. The study allows the following conclusions to be drawn:

1) Roofing tile bioreceptivity increased with apparent porosity (measured as water absorption), enabling possible water retention, which encourages microbiological growth. Roughness also fostered micro-organism adhesion and increased bioreceptivity.

2) In the roofing tiles coated with a ceramic glaze, bioreceptivity was practically zero after short exposure times because surface water absorption was also very low $(<1 \%)$. 
3) After long exposure times (several months), under very favourable colonization conditions, the glazed roofing tiles were colonized, whereas glazed roofing tiles covered with a $\mathrm{TiO}_{2}$ photocatalytic coating exhibited practically no biological growth under the tested conditions.

4) The test method used enabled the bioreceptivity of various red ceramic roofing tiles of different composition, roughness, porosity, without and with different coatings to be determined, since the method is unaffected by colour, roughness, or type of coating.

5) In order to design ceramic roofing tiles with enhanced bio-resistance, apparent porosity and roughness need to be minimized, while the application of a ceramic glaze and a $\mathrm{TiO}_{2}$ photocatalytic coating provides added resistance to biocolonization.

6) Further research is needed to establish the appropriate exposure time of the accelerated laboratory test method used, in order to reflect actual weathering conditions as precisely as possible and to better understand the effects, efficiencies, and durability of photocatalytic coatings in relation to biocolonization.

\section{Acknowledgements}

This study has been funded by the Spanish Ministry of Education and Science, through the PET2007-0080 project conducted in the frame of the R\&D\&I Plan in the PETRI (Projects for stimulating research results transfer) programme.

The authors also wish to thank Dr. José Enrique Frías (Biological Cultures Service, Instituto de Biología Vegetal y Fotosíntesis, CSIC, Seville, Spain) for providing the Oscillatoria strain used. 


\section{References}

[1] Chen, J; Blume, H.P.; Beyer, L. Weathering of rocks induced by lichen colonization - a review. Catena, 2000, 39, 121-146.

[2] Prieto, B.; Silva, B.; Rivas, T.; Wierzchos, J.; Ascaso, C. Mineralogical transformation and neoformation in granite caused by the lichens Tephromela atra and Ochrolechia parella. Int. Biodeterior. and Biodegrad., 1997, 40 (2-4), 191-199.

[3] Adamo, P.; Violante, P. Weathering of rocks and neogenesis of minerals associated with lichen activity. Appl. Clay Sci., 2000, 16, 229-256.

[4] Kiurski, J.; et.al. Biochemical corrosion of ceramic roofing tiles by lichen actions. Build. Mater., 2005, 54, 340-343.

[5] Schatz, A. Chelation in nutrition. Soil microorganisms and soil chelation. The pedogenic action of lichens and lichen acids. J. Agric. Food Chem., 1963, 11 (2), 112-118.

[6] Ranogajec, J.; Markov, S.; Kiurski, J.; Radeka, M.; Ducman, V. Microbial deterioration of clay roofing tile as a function of the firing temperature. J. Am. Ceram. Soc., 2008, 91 (11), 3762-3767.

[7] Radeka, M.; Ranogajec, J.; Kiurski, J.; Markov, S.; Marinković-Nedučin, R. Influence of lichen biocorrosion on the quality of ceramic roofing tiles. J. Eur. Ceram. Soc., $2007,27,1763-1766$.

[8] Radomir M. Vasic. Surface roofing tile scaling due to the moisture expansion phenomenon. Key Eng. Mater., 1997, 132-136, 1665-1668.

[9] Laiz, L.; González, J.M.; et. al. Microbial assessment of the biological colonization on roofing tiles. In: Heritage, Weathering and Conservation. London: Taylor \& Francis, 2006. pp. 349-353. Heritage, Weathering and Conservation Patrimonio, Deterioro y Conservación - (HWC-2006) Madrid 21 - 24 June 2006. 
[10] Portillo, M.C.; Gazulla, M.F.; Sánchez, E.; González, J.M. A procedure to evaluate the resistance to biological colonization as a characteristic for product quality of ceramic roofing tiles. J. Eur. Ceram. Soc., 2011, 31, 351-359.

[11] Hadnadjev, M.; et. al. Design of self-cleaning $\mathrm{TiO}_{2}$ coating on clay roofing tiles. Philos. Mag., 2010, 90 (22), 2989 - 3002.

[12] Fassier, M.; et. al. Photocatalytic activity of anatase coatings on fired clay substrates. J. Eur. Ceram. Soc., 2009, 29(4), 565-570.

[13] Bagán, V.; Enrique J.E.; Mallol, G.; Sánchez, E. Influence of process variables on the quality of impervious tiles. Tile and Brick Int., 1990, 6(5), 35-42.

[14] Escardino, A.; Ibáñez, M.J.; Blasco, A.; Amorós, J.L. Empleo del rugosímetro para el estudio cuantitativo de la degradación, por abrasión, de vidriados cerámicos. Cerámica Información, 1993, 186, 16-30.

[15] Muynck, W. de. Microbial interaction with mineral building materials. Ghent: Ghent University, 2009 [PhD thesis].

[16] Sánchez, E.; García, J.; Sanz, V.; Ochandio, E. Raw material selection criteria for the production of floor and wall tiles. Tile and Brick Int., 1990, 6, 15-21.

[17] Belie, N. DE; Ramirez, A.M.; Muynck, W. de When green is not clean. J. Eur. Coat., 2010, 5, 40-45. 


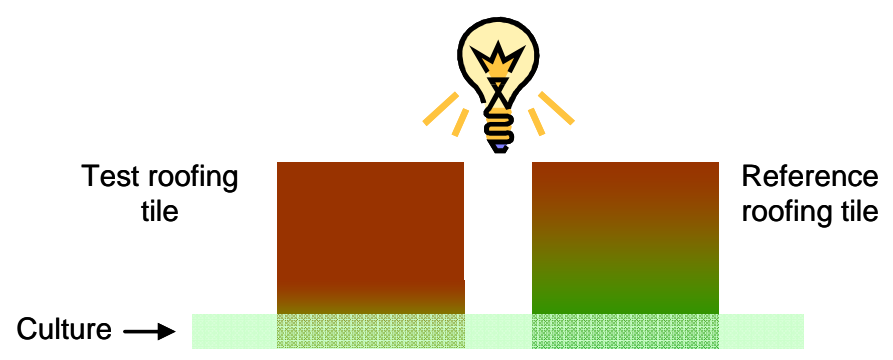

Figure 1: Schematic illustration of the set-up used for the bioreceptivity test
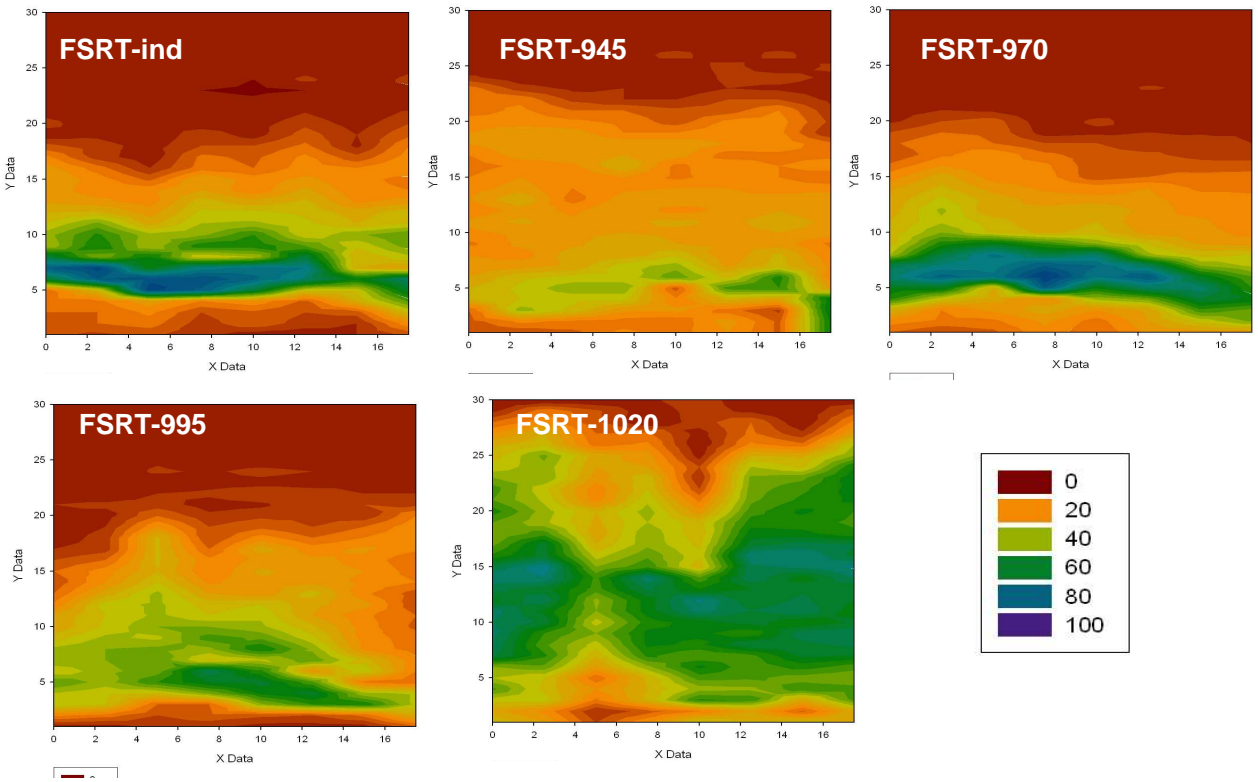

Figure 2: PAM fluorometer measurements of the standard red roofing tiles fired at different temperatures (FSRT series). Fluorescence (biocolonization) is expressed in the range $0(\square)$ minimum to $100(\square)$ maximum
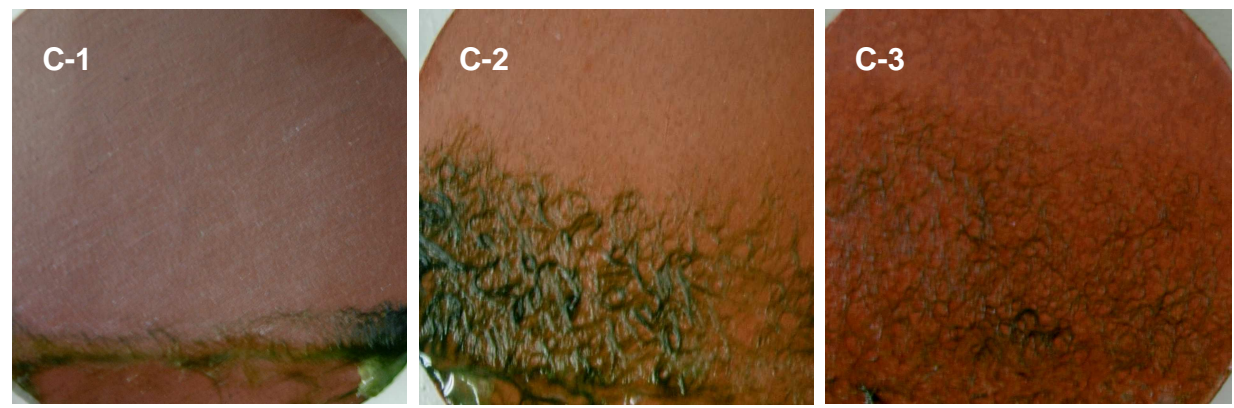

Figure 3: Photographs of the fired test pieces obtained from clay mixtures C-1, C-2, and C-3 after the 14-day biocolonization test 

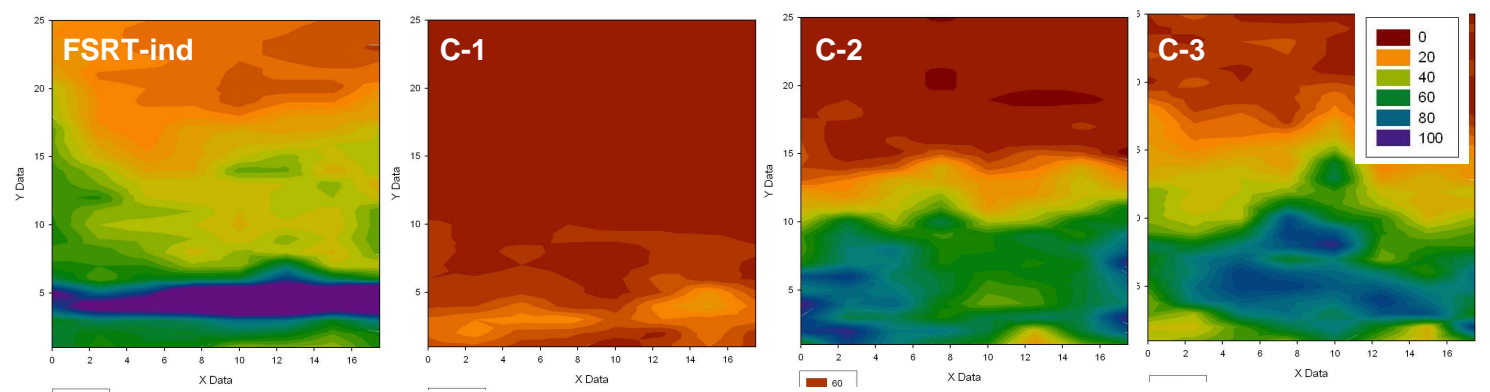

Figure 4: PAM fluorometer measurements of the fired test pieces obtained from clay mixtures C-1, C-2, and C-3. Fluorescence (biocolonization) is expressed in the range 0 ( $\square$ ) minimum to $100(\square)$ maximum

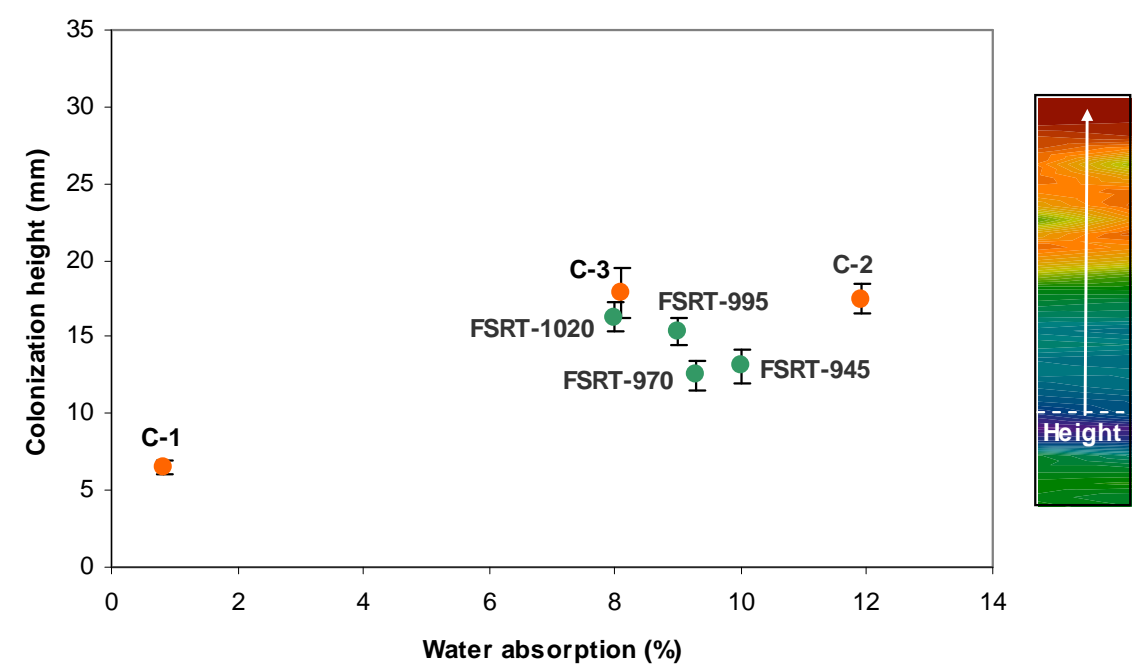

Figure 5: Colonization height versus water absorption of the FSRT series and of the fired C-1, C2, and C-3 test pieces
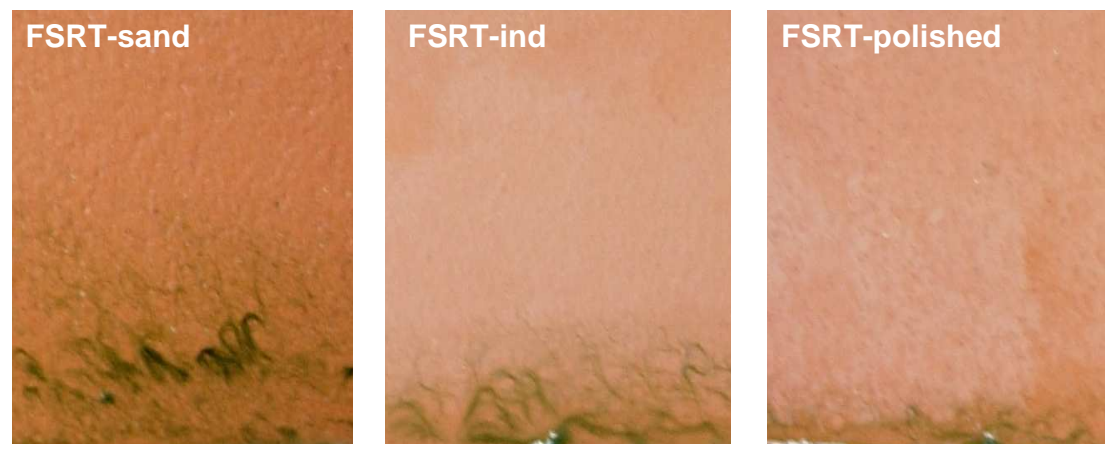

Figure 6: Photographs of the fired standard red roofing tile (FSRT-ind), sanded standard red roofing tile (FSRT-sand), and polished standard red roofing tile (FSRT-polished) after the 10-day biocolonization test 

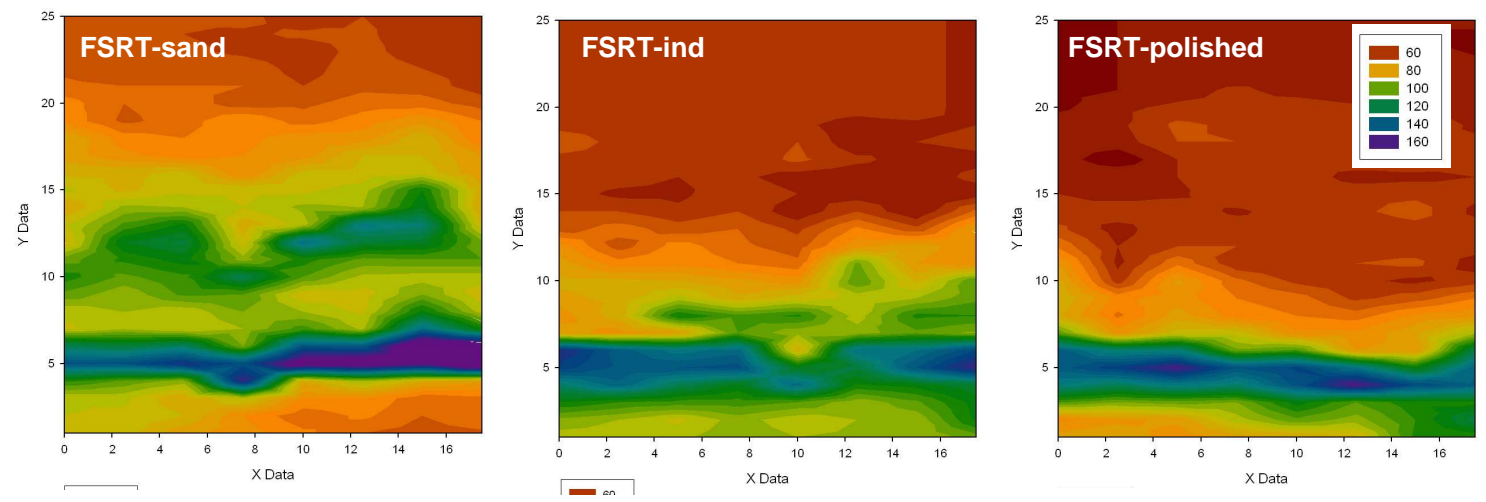

Figure 7: PAM fluorometer measurements of the fired standard red roofing tile (FSRT-ind), sanded standard red roofing tile (FSRT-sand), and polished standard red roofing tile (FSRT-polished) after the 10-day biocolonization test. Fluorescence (biocolonization) is expressed in the range $0(\square)$ minimum to $100(\square)$ maximum

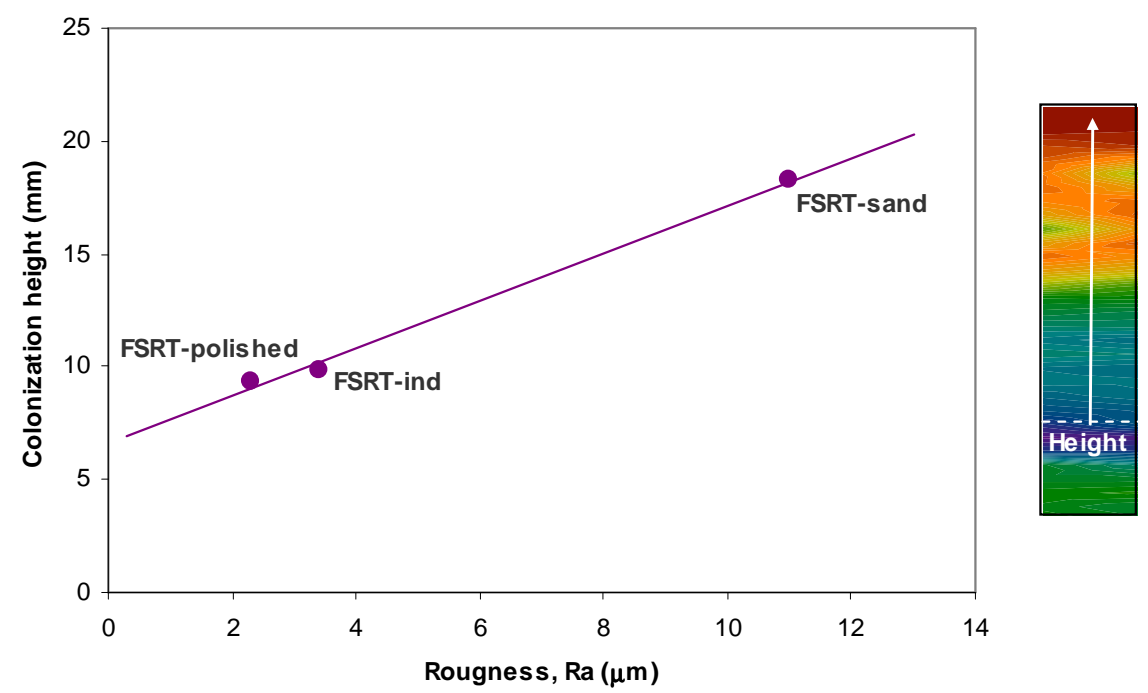

Figure 8: Relationship between roofing tile roughness $\left(R_{a}\right)$ and colonization height 

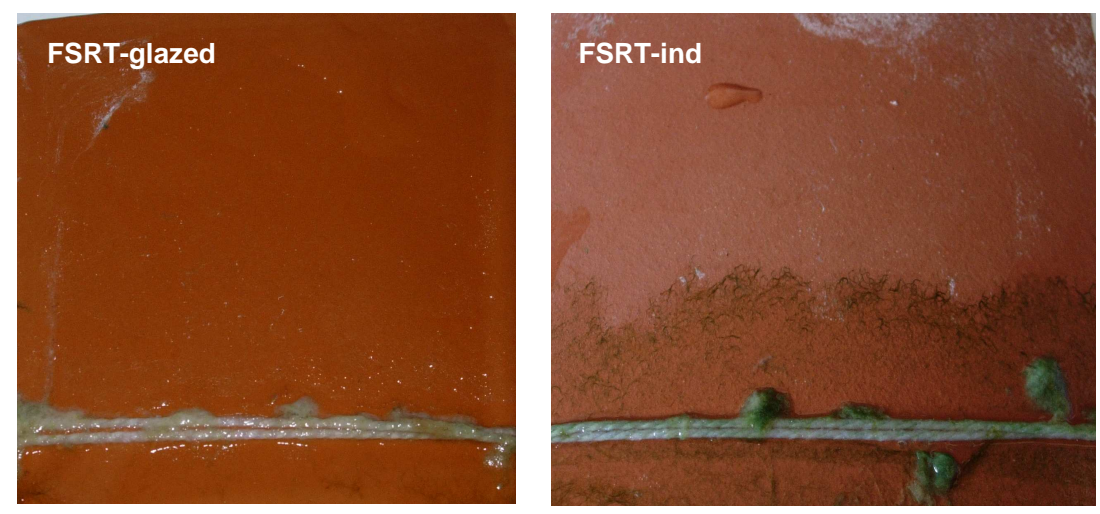

Figure 9: Photographs of the fired glazed standard red roofing tile (FSRT-glazed) and standard red roofing tile (FSRT-ind) after the 15-day biocolonization test
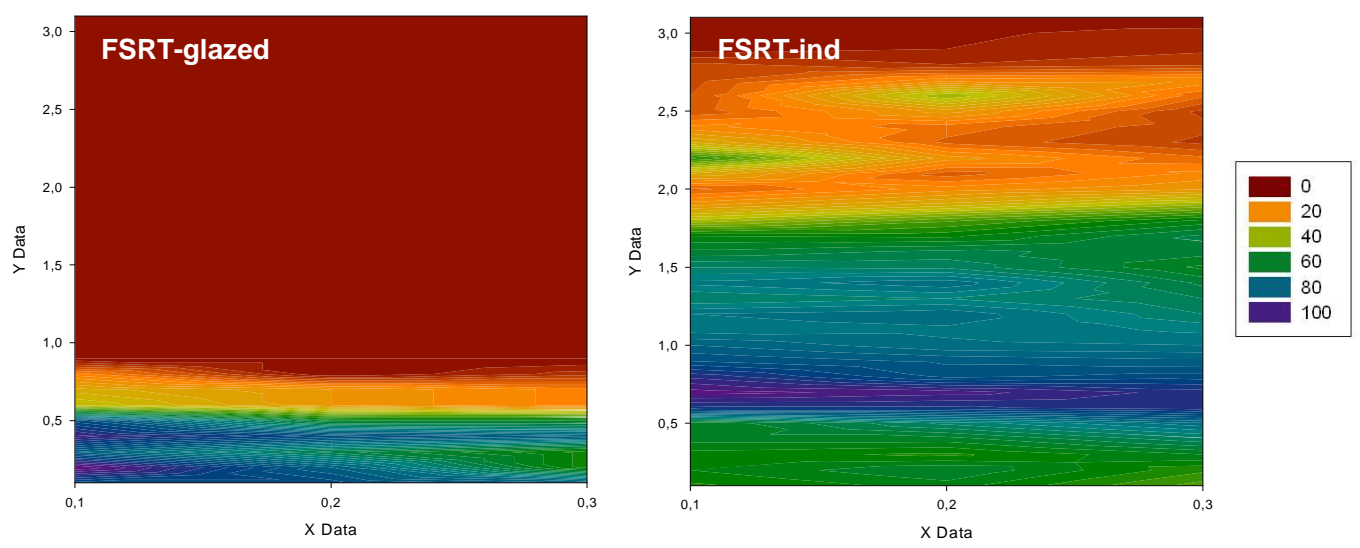

Figure 10: PAM fluorometer measurements of the fired glazed standard red roofing tile (FSRTglazed) and standard red roofing tile (FSRT-ind) after the 15-day biocolonization test. Fluorescence (biocolonization) is expressed in the range $0(\square)$ minimum to $100(\square)$ maximum
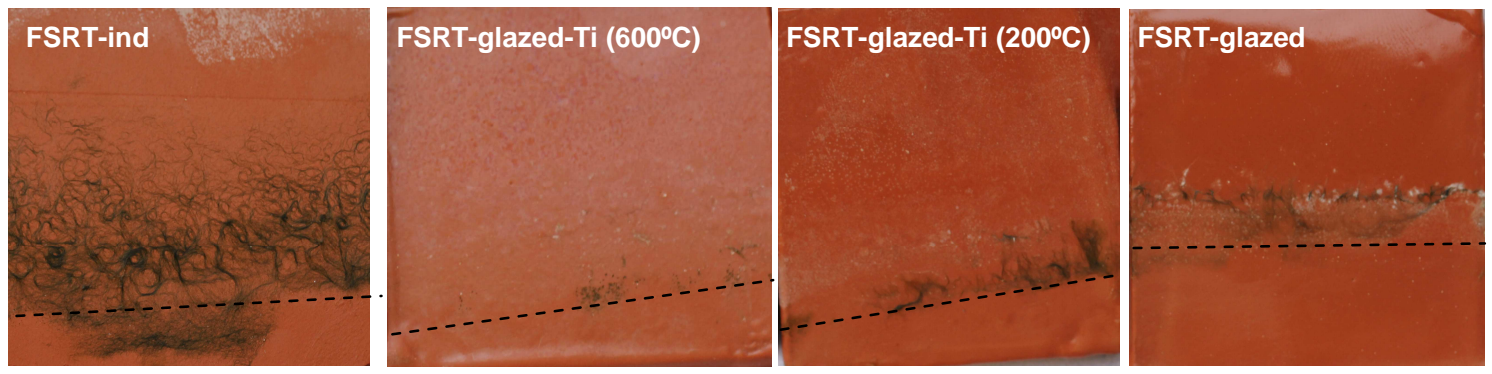

Figure 11: Photographs of the glazed standard red roofing tiles with a photocatalytic coating (FSRT-glazed-Ti) heat treated at either $200{ }^{\circ} \mathrm{C}$ or $600{ }^{\circ} \mathrm{C}$ and subjected to the 30 -day biocolonization test. For comparative purposes, the photographs are also shown of FSRT-ind and FSRT-glazed samples after the same biocolonization time 

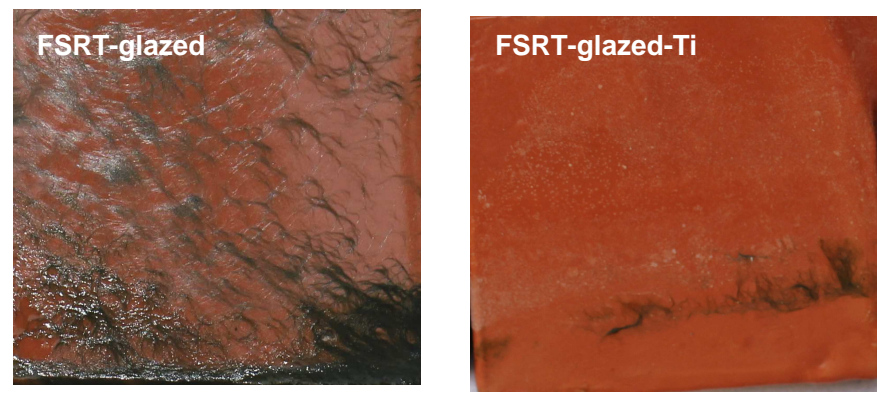

Figure 12: Photographs of the glazed standard red roofing tiles without and with a photocatalytic coating (FSRT-glazed and FSRT-glazed-Ti, respectively) after the 4month biocolonization test 